\title{
Nanomedicine in cerebral palsy
}

This article was published in the following Dove Press journal:

International Journal of Nanomedicine

31 October 2013

Number of times this article has been viewed

\author{
Bindu Balakrishnan' \\ Elizabeth Nance' \\ Michael V Johnston ${ }^{2}$ \\ Rangaramanujam Kannan ${ }^{3}$ \\ Sujatha Kannan' \\ 'Department of Anesthesiology \\ and Critical Care Medicine, Johns \\ Hopkins University; Baltimore, MD, \\ USA; ${ }^{2}$ Department of Neurology and \\ Pediatrics, Kennedy Krieger Institute, \\ Baltimore, MD, USA; ${ }^{3}$ Department \\ of Ophthalmology, Center for \\ Nanomedicine, Johns Hopkins \\ University, Baltimore, MD, USA
}

\begin{abstract}
Cerebral palsy is a chronic childhood disorder that can have diverse etiologies. Injury to the developing brain that occurs either in utero or soon after birth can result in the motor, sensory, and cognitive deficits seen in cerebral palsy. Although the etiologies for cerebral palsy are variable, neuroinflammation plays a key role in the pathophysiology of the brain injury irrespective of the etiology. Currently, there is no effective cure for cerebral palsy. Nanomedicine offers a new frontier in the development of therapies for prevention and treatment of brain injury resulting in cerebral palsy. Nanomaterials such as dendrimers provide opportunities for the targeted delivery of multiple drugs that can mitigate several pathways involved in injury and can be delivered specifically to the cells that are responsible for neuroinflammation and injury. These materials also offer the opportunity to deliver agents that would promote repair and regeneration in the brain, resulting not only in attenuation of injury, but also enabling normal growth. In this review, the current advances in nanotechnology for treatment of brain injury are discussed with specific relevance to cerebral palsy. Future directions that would facilitate clinical translation in neonates and children are also addressed.
\end{abstract}

Keywords: dendrimer, cerebral palsy, neuroinflammation, nanoparticle, neonatal brain injury, G4OH-PAMAM

\section{Cerebral palsy: scope of the problem}

Cerebral palsy (CP) is a chronic childhood disability with no effective cure; it results in a significant personal, social, and economical burden. CP was first described by an orthopedic surgeon William John Little in 1862, who noted that newborns who underwent asphyxia or mechanical injury before or during childbirth developed rigidity and distortion of limbs later in life. ${ }^{1}$ Initially, CP was considered solely to be a movement disorder associated with white matter injury, mainly because the characteristic signs observed in these patients are abnormalities in movement and coordination that include spasticity, rigidity, ataxia, and muscle weakness. ${ }^{2}$ However subsequent studies have shown that apart from white matter injury, grey matter abnormalities in the cortex and subcortical structures contribute to developmental delays, cognitive disturbances, and psychomotor abnormalities in these patients. ${ }^{3-6}$ To include these symptoms, CP is now more comprehensively defined as a "group of permanent disorders of the development of movement and posture, causing activity limitation that is attributed to nonprogressive disturbances that occurred in the developing fetus or the infant brain. [These] are often accompanied by disturbances of sensation, perception, cognition, communication and behavior."7
Correspondence: Sujatha Kannan

Department of Anesthesiology and Critical Care Medicine, Johns Hopkins University, Baltimore, MD 2 I 205, USA

Tel + I 4109557610

Email skannan3@jhmi.edu (c) (7) (5) 2013 Balakrishnan et al. This work is published by Dove Medical Press Ltd, and licensed under Creative Commons Attribution - Non Commercial (unported, v3.0) License. The full terms of the License are available at http://creativecommons.org/licenses/by-nc/3.0/. Non-commercial uses of the work are permitted without any Information on how to request permission may be found at: http://www.dovepress.com/permissions.php 
Cerebral palsy is the most common cause of childhood disability. ${ }^{8}$ The US Centers for Disease Control and Prevention (CDC) has reported a worldwide prevalence of $1.5-4$ per 1,000 live births, with an average lifetime cost of $\sim 1$ million dollars per person in the US. ${ }^{9}$ The autism and developmental disabilities monitoring network conducted a surveillance of $\mathrm{CP}$ among 8-year-old children and reported a prevalence of 3.3 per 1,000 children, with a male/female ratio of $1.4: 1{ }^{10}$ The incidence of $\mathrm{CP}$ is strongly associated with gestational age, and prematurity is considered to be a leading risk factor for the development of $\mathrm{CP} .{ }^{11}$ Even though technological advancements in neonatal intensive care units have resulted in improved survival of premature and very low birth weight infants, the incidence of CP has not decreased. ${ }^{12,13}$ Whereas $5 \%-10 \%$ of premature infants develop motor disability, a much larger proportion ( $40 \%-50 \%)$ develop some form of cognitive and/or behavioral abnormality. ${ }^{14,15}$ However, there is at present no cure for perinatal/neonatal brain injury and CP. Neuroprotective strategies such as therapeutic hypothermia, which is currently considered to be the most promising approach to improved outcomes, results in only an $11 \%$ decrease in risk of death or severe disability. ${ }^{16}$ Patient management is primarily confined to methods of rehabilitation for alleviating symptoms and improving quality of life. Despite these advances, decreasing the incidence of $\mathrm{CP}$ will not be possible until new treatments for the disorder can be discovered.

Several risk factors, such as very low birth weight, prematurity, intraventricular hemorrhage, multiple pregnancy, chorioamnionitis, hypoxia, neonatal encephalopathy, fetal infections, and genetic factors, have been found to be strongly associated with $\mathrm{CP} \cdot{ }^{17-20}$ The primary pathophysiological mechanisms that result in $\mathrm{CP}$ can be broadly classified as: (1) hypoxia and ischemia that leads to a cascade of excitooxidative events in the brain; ${ }^{12}$ (2) intrauterine infections/ inflammation resulting in a fetal inflammatory response syndrome and neuroinflammation; ${ }^{19}$ and (3) genetic or other congenital causes. ${ }^{20}$ These mechanisms may often work in combination. Although CP can have multiple etiologies, neuroinflammation and periventricular leukomalacia (PVL) are common pathological substrates..$^{21}$ Inflammation in the central nervous system (CNS) is mediated by immune cells in the brain that include microglia and infiltrating macrophages. Activated microglia and astrocytes are implicated in the development of a number of neurodegenerative disorders both in children and adults. Periventricular leukomalacia, the pathophysiological substrate associated with $\mathrm{CP}$ in humans, is characterized by focal necrosis around the ventricles, and diffuse microglial and astrocyte activation in the immature white matter. ${ }^{21}$

\section{Glial activation and neonatal brain injury}

Microglia and astrocytes, the two major glial cells in the brain, play a pivotal role in CNS injury and repair. Of the two, microglia are crucial for remodeling and growth in the developing brain. During the process of human fetal development, microglia are present along the white matter tract from late second trimester onward $\mathrm{d}^{22}$ and perform a supportive role in myelinogenesis and axonogenesis. ${ }^{23}$ Though the primary function of microglia during development is to provide a supportive role, their presence can accentuate the vulnerability of the developing brain to various brain insults.

Activated microglia/macrophages play a key role after CNS injury and can be either protective or detrimental. ${ }^{24-28}$ However, the microglial/macrophage response may depend on the type (infection/inflammation versus hypoxic ischemia) and the timing of injury (acute versus chronic). Suppressing the immediate microglial response after an hypoxic-ischemic insult in a neonatal stroke rat model has been shown to be deleterious. ${ }^{29}$ However, a proinflammatory activation of these cells can result in an exaggerated, ongoing inflammatory response that persists long after the injury, with formation of free radicals, excitotoxic metabolites, and proinflammatory cytokines, leading to diffuse white and grey matter injury as seen in $\mathrm{CP}^{26-28}$ In severe inflammation, astrocytes that normally participate in the protection of neurons and in preventing oxidative injury, are unable to maintain their neuroprotective role. ${ }^{30} \mathrm{An}$ increased number of activated microglia have been noted along the white matter tract in autopsy specimens of patients with PVL. ${ }^{21}$ In response to an immune activation, microglial cells and astrocytes in the fetal and newborn brain can secrete cytokines such as IL1 $\beta$ and TNF $\alpha$, causing injury to developing oligodendrocytes and neuronal progenitors. ${ }^{31-34}$ Similarly, studies have demonstrated the presence of hypertrophic astrocytes in kittens and fetal sheep following LPS injection. ${ }^{35,36}$ Diffuse astrogliosis is a major pathological feature in white matter injury and is associated with arrest of oligodendrocyte maturation. ${ }^{30}$ Similarly, we have shown that intrauterine administration of lipopolysaccharide leads to intense proinflammatory microglial activation in the periventricular region of the fetal brain that corresponds with the extent of motor deficits in the neonatal rabbit. ${ }^{37,38}$

There is a growing body of literature to suggest that strategies to target neuroinflammation can potentially 
decrease progression and increase the therapeutic window in neurodegenerative diseases. ${ }^{39-42}$ Therefore, an approach that attenuates neuroinflammation in a targeted manner may be beneficial in treating perinatal brain injury, improving brain development and motor function in CP. However, treatment of disorders such as CP is challenging because (1) inflammation and injury are often diffuse in the white matter, precluding local brain delivery; (2) postnatal treatment of a prenatal injury to the brain is not expected to result in improvement in motor function; and (3) transport of drugs across the bloodbrain barrier (BBB) is often difficult to achieve. An ideal therapeutic agent targeted to the brain should have minimal systemic effects; should be able to cross the BBB only in the presence of injury; and must exert its effect specifically in the cells involved in injury. A critical balance of all these characteristics would be required for the therapeutic to be effective in clinical trials. Moreover, since CP is a clinical diagnosis that is often made later in life, early treatment would be directed to 'at-risk' patients. Hence a therapeutic agent that has minimal side effects and is not effective when there has been no insult to the brain would be most likely to be clinically translated.

\section{Nanoparticles for the treatment of brain injury}

Despite the advances in CNS therapies and increasing understanding of disease origin and progression, treatment of CNS diseases remains a significant challenge. There is a paucity of studies exhibiting evidence of a critical correlation between early detection, prognosis, and treatment success. Nanotechnology-based approaches are providing potential platforms for CNS therapy. The physicochemical properties of the nanoparticles can be tailored to overcome the $\mathrm{BBB}^{43}$ and to improve penetration and diffusion through the brain parenchyma, ${ }^{44}$ allowing for controlled, sustained release of a therapeutic. These approaches have shown significant promise in preclinical studies for the treatment of many CNS diseases, including cancer, neuroinflammation, and neurodegeneration. Among the different nanoparticle platforms, dendrimers show significant promise as drug delivery vehicles due to their small size, tailorable end groups, and favorable biosafety profile.

\section{Dendrimers as drug delivery vehicles}

Dendrimers, soft globular molecules about 3-10 nm in size, are emerging as promising candidates for diagnostic platforms and targeted drug and gene delivery vehicles (Figure 1). Recently, promising efficacy results have been reported in preclinical studies, including cancer, systemic inflammation and rheumatoid arthritis. ${ }^{45-48}$ The small size, branching architecture, and high density of tailorable surface functional groups can provide significant advantages for CNS and BBB transport. Polyamidoamine (PAMAM) dendrimers are widely studied due to their commercial availability. The growing interest in the PAMAM dendrimer as a vehicle for drugs is mainly attributable to the ability of the nanoparticle to enhance the selectivity and stability of the drug. In vivo administration of PAMAM dendrimer grafts attached to the anticancer drug 5-fluorouracil (5-FU) in rats has shown to increase its bioavailability compared with the free drug. ${ }^{49}$ The efficacy of nonsteroidal anti-inflammatory drugs such as indomethacin has been shown to be enhanced by conjugation of the drug with folic acid-coupled dendrimers in a rat model of arthritis. ${ }^{50}$ Cell-specific internalization of a dendrimer-drug conjugate has been reported to overcome the resistant action of P-glycoprotein in tumor cells. Kukowska-Latallo et $\mathrm{al}^{51}$ have reported that when acetylated dendrimer conjugated with folic acid and coupled with methotrexate was injected into immunodeficient mice bearing tumor cells, there was increased uptake of drug into tumorspecific cells. Poly(ethylene glycol)-lysine dendrimers have been used as a carrier to deliver nitric oxide to alleviate the symptoms of atherosclerosis. ${ }^{52}$ Recent studies by Iezzi et al and Kannan et al have shown that hydroxyl-functionalized PAMAM dendrimers can target neuroinflammation in the retina upon intravitreal administration and provide sustained neuroprotection for at least 30 days through targeted, intracellular delivery of a steroid. ${ }^{39}$

\section{Dendrimer nanodevices for the treatment of cerebral palsy}

$\mathrm{CP}$ has always been a challenging neurological disorder for development of therapies because of the multifocal nature of the brain injury and the difficulty in early diagnosis unless symptoms are very severe. However, recent studies have shown that neuroinflammation associated with perinatal brain injury can be detected by serum biomarkers that persist even after birth, or by imaging using positron emission tomography (PET) to noninvasively detect persistent activated microglia in the brain. ${ }^{53,54}$ Our recent studies in rabbit kits with CP born to mothers administered intrauterine endotoxin revealed the significant potential for nanomedicine approaches in this challenging disorder that has no effective cure. ${ }^{42,55}$ When G4OH-PAMAM dendrimers were administered intravenously to newborn rabbits with $\mathrm{CP}$, the dendrimers crossed the $\mathrm{BBB}$ and selectively localized in cells associated with 


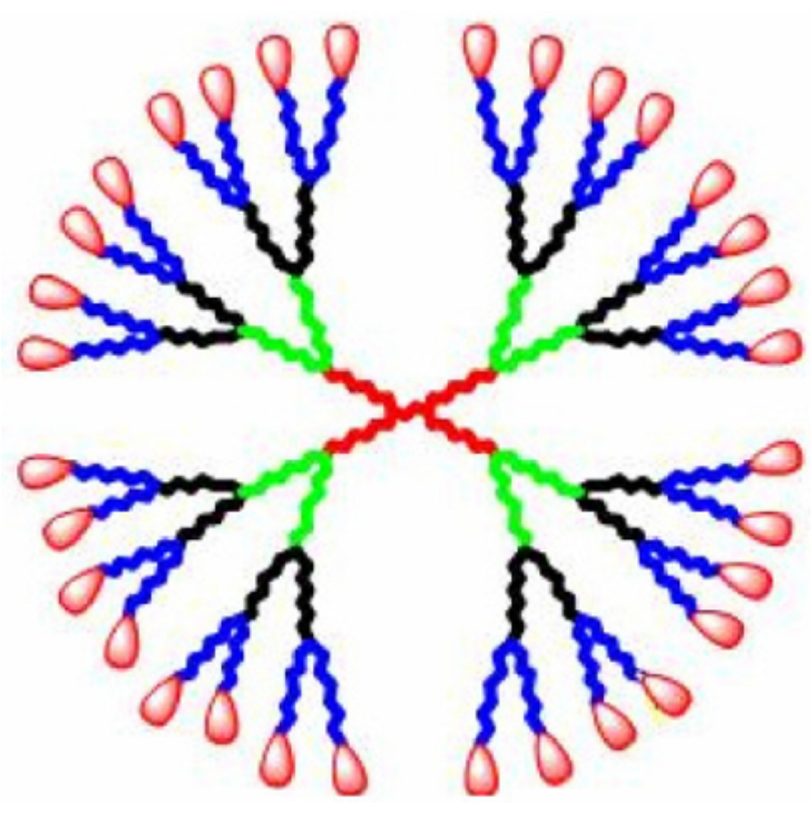

Figure I Schematic of dendrimer.

neuroinflammation. This selective localization into activated microglia and astrocytes was seen in CP kits, with minimal brain uptake and localization shown in healthy kits. To take advantage of this selective localization, we coupled $\mathrm{N}$-acetyl cysteine (NAC) to these dendrimers, and engineered them for tailored intracellular release. NAC has both antioxidant and anti-inflammatory properties, and is widely used clinically in children and adults; ${ }^{56}$ it is being evaluated in several clinical trials. ${ }^{57-61}$ Improved delivery and efficacy with a safe drug, already in clinical use for other applications and undergoing clinical trials for neuroinflammatory disorders, provides an easier path to translation.

For dendrimer-NAC conjugates, the NAC is released from dendrimer in a glutathione (GSH)-dependent manner in the cells, decreasing the inflammatory response, decreasing microglial and astrocyte activation, and improving white matter injury in the kits (Figure 2). Four days after intravenous administration of D-NAC, there was a dramatic improvement in motor function of CP kits, which was associated with significant improvement in neuronal injury, myelination, oxidative injury, and inflammation (Figure 3). When NAC was conjugated to the dendrimer, it was 10 - to 100 -fold more effective than in its free form. More importantly, these studies suggest that targeted, timely, postnatal attenuation of a prenatal brain injury can be effective. ${ }^{41,42}$ NAC is normally used in very high doses because of the poor bioavailability resulting from protein binding of its - SH groups. ${ }^{62}$ Moreover, L-cysteine has been shown to have neurotoxic effects, resulting in neuronal death from overactivation of NMDA receptors on neurons. ${ }^{63}$ Inflammation also causes depletion of GSH in astrocytes, with a loss of their normal neuroprotective role. ${ }^{30}$ We expect that delivery of NAC specifically to activated astrocytes and microglia will result in suppression of neuroinflammation and oxidative stress along with replenishment of GSH in astrocytes, thereby leading to sustained improvement of myelination, reduction of white matter injury, and improved neurobehavioral outcomes in neonatal mice and rabbits with PVL. Hence, selective delivery of NAC to glial cells may help decrease neuronal toxicity.

Intraventricular and intraparenchymal injection of cationic G4-NH2 dendrimers has shown that dendrimers diffuse into the brain parenchyma and are endocytosed into specific compartments of neurons and microglia. ${ }^{64}$ The capacity of the G4 dendrimer to be internalized into the neurons and activated glial cells reveals the intrinsic behavior of this nanocarrier and its therapeutic potential in the field of nanomedicine for neurological disorders.

A summary of recent preclinical studies involving nanoparticle-based therapies for neuroinflammation and neurodegenerative disorders is provided in Table 1. Most of the studies have involved animal models of adult neurodegenerative disorders using nanoplatforms that have typically ranged in size from 5-100 nm. Pediatric neurological disorders have typically not been a focus of the studies. Therapeutic nanoparticles used in preclinical neuro-oncology studies has been extensively covered in two recent reviews. ${ }^{65,66}$ Unfortunately, even though many nanomedicine platforms have shown success in preclinical studies, there are no clinical trials that the present authors are aware of that incorporate the use of nanoparticles for the treatment of CNS diseases other than CNS tumors or malignancies, as indicated in Table 2.

Apart from maternal inflammation, hypoxia-ischemia is one of the major causes of perinatal and neonatal brain injury resulting in $\mathrm{CP}^{6}$ Therefore, therapies that have been effective in adult models of stroke, or in adult neuroinflammatory or neurodegenerative disorders such as Alzheimer's, or multiple sclerosis, could also have potential benefits for treatment of neonatal brain injury. Poly(ethylene glycol)-coated chitosan nanospheres that were functionalized with transferrin receptor monoclonal antibody for transportation across the $\mathrm{BBB}$ and loaded with N-benzyloxycarbonyl-Asp(OMe)Glu(OMe)-Val-Asp(OMe)-fluoromethylketone (Z-DEVDFMK), a relatively specific caspase-3 inhibitor, resulted in decreased infarct size, along with functional improvement in an adult animal model of stroke, when administered 


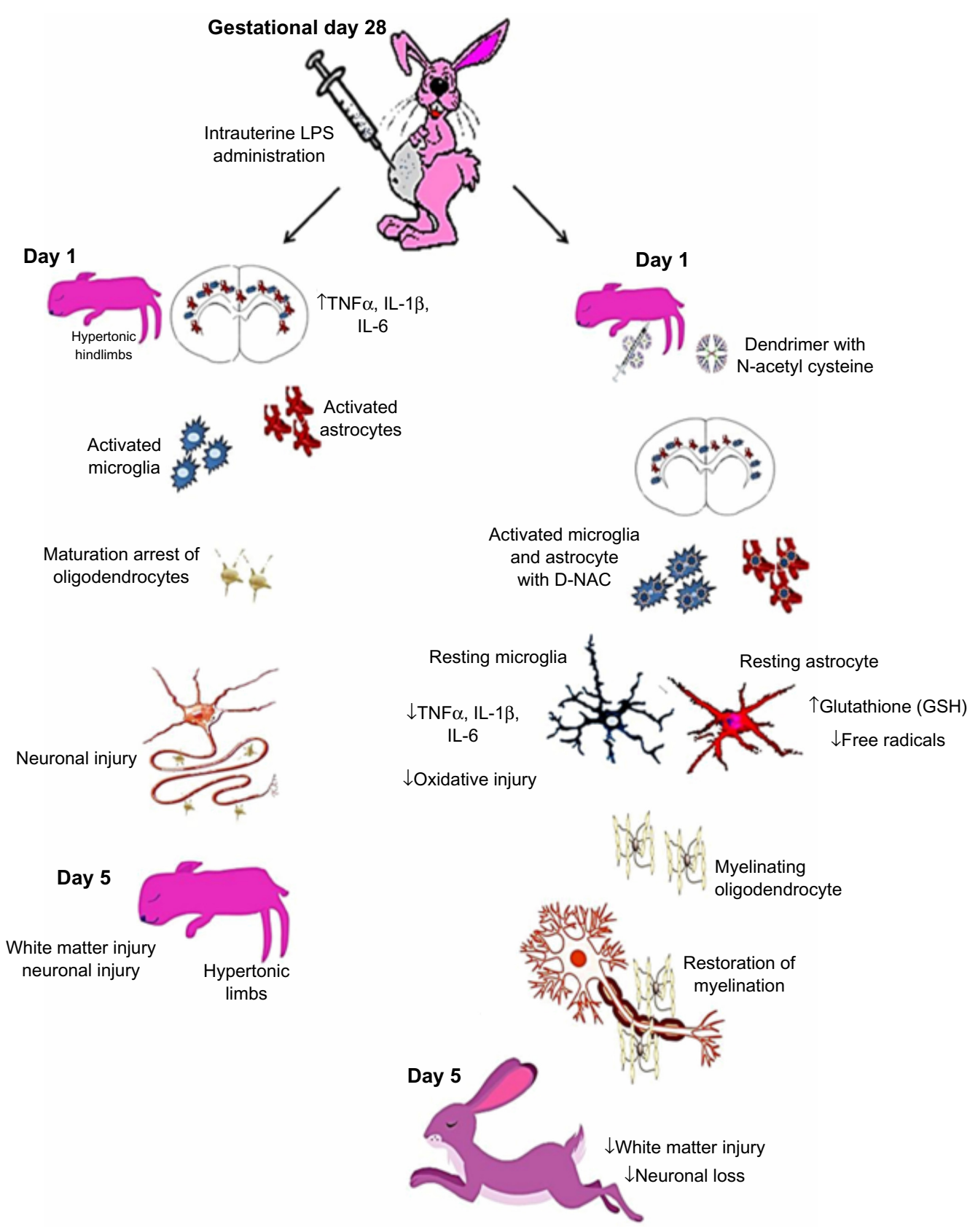

Figure 2 Diagrammatic representation of D-NAC treatment in rabbit kits with CP.

Notes: Maternal intrauterine infection/inflammation by LPS treatment results in increased proinflammatory cytokines, leading to activated microglia and astrocytes in the fetus. The activated glial cells further secrete proinflammatory cytokines and free radicals, resulting in oxidative injury, maturation arrest of premature oligodendrocytes, and white matter injury. Intravenous administration of D-NAC in CP kits on postnatal day I results in uptake of the dendrimer drug conjugates by activated microglia and astrocytes. Once inside the glial cells, NAC increases the GSH level, decreasing the release of proinflammatory cytokines and synthesis of free radicals with restoration of myelination by oligodendrocytes. Thus D-NAC treatment ameliorates the motor deficits in rabbit kits with CP.

Abbreviations: D-NAC, dendrimer-N acetyl cysteine; CP, cerebral palsy; LPS, lipopolysaccharide; GSH, glutathione; TNF, tumor necrosis factor; IL, interleukin; NAC, $\mathrm{N}$-acetyl cysteine.

intravenously either as a pretreatment or within 2 hours after injury. ${ }^{84}$ e-PAM-R, a biodegradable arginine ester of $\mathrm{G} 4 \mathrm{OH}$ PAMAM dendrimer, was effective in transfection of high mobility group box-1 (HMGB1) in neurons and astrocytes, and was neuroprotective when administered intracranially as a pretreatment prior to the insult. ${ }^{85}$ Intraperitoneal administration of lipid core nanocapsules loaded with drugs such as indomethacin or resveratrol resulted in decreased expression of activated microglia and proinflammatory cytokines in a rat model of Alzheimer's disease. Although the actual presence of the lipid core nanocapsules was not demonstrated in the brain, an increased concentration of 


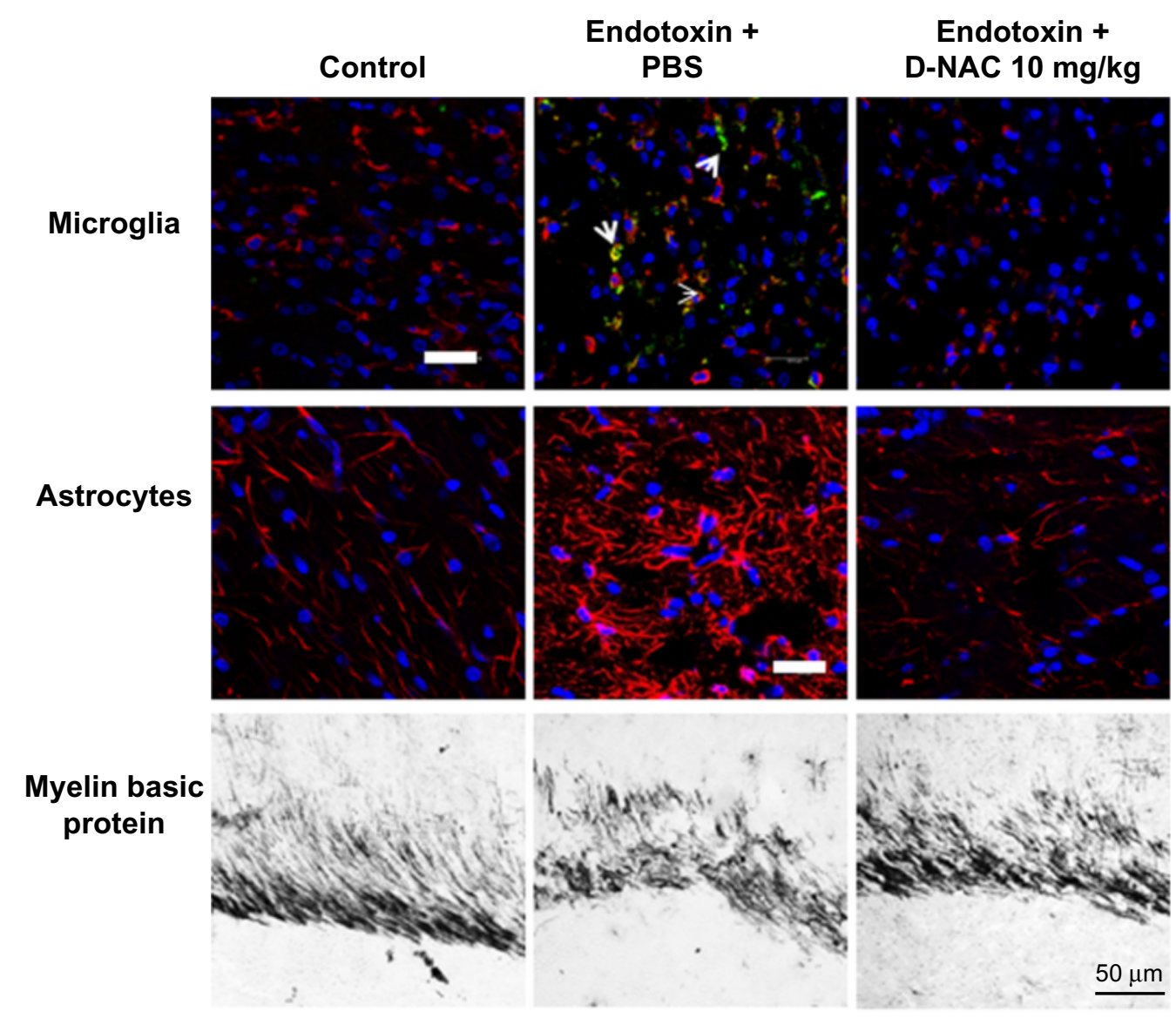

Figure 3 Representative images of microglia, astrocytes and myelin basic protein in control, endotoxin-saline and dendrimer $\mathrm{N}$-acetylcysteine-treated groups in postnatal day 5 rabbit kits.

Notes: Intrauterine maternal infection/inflammation results in activated microglia (red = lectin, arrow indicates green $=$ CDI Ib), activated astrocytes (GFAP stain in red) and decreased myelination (myelin basic protein stain) in the white matter region of endotoxin group. Treatment of the endotoxin kit with D-NAC I0 mg/kg results in decreased activation of microglia (with decreased CDI Ib expression) and astrocytes followed by restoration of myelin on postnatal day 5 . Nuclear stain $=$ DAPI (blue). Scale bar $=20$ microns for GFAP and lectin and 50 microns for the myelin stain.

Abbreviations: D-NAC, dendrimer N-acetylcysteine; GFAP, glial fibrillary acidic protein; DAPI, 4',6-diamidino-2-phenylindole; PBS, phosphate buffer solution.

the drug was demonstrated in the brain tissue. ${ }^{70}$ Several of these therapies have focused on pretreatment or treatment immediately after the injury, which may not be clinically relevant in the treatment of perinatal or neonatal brain injury resulting in $\mathrm{CP}$, as the injury often occurs in utero and before birth. However, because the pathophysiology involving activated microglia and inflammatory cytokines resulting in hypomyelination and axonal loss, may have similarities, some of these therapies may have potential applications in the treatment of CP.

\section{Therapeutic window and clinical considerations}

Although $\mathrm{CP}$ is considered to be nonprogressive, the developing brain continues to undergo changes based on the developmental stage, to adapt to the injury. ${ }^{105}$ This may be dictated by ongoing inflammation in the brain, as evidenced by preclinical studies and postmortem studies in humans with periventricular leukomalacia that shows persistent, diffuse astro- and microgliosis along the periventricular region of the brain. ${ }^{106,107}$ Positron emission and postmortem studies in traumatic brain injury have demonstrated activation of microglia in the thalamus several years after injury. ${ }^{108,109}$ Persistent activation of microglia has been observed in other neurodegenerative diseases such as Parkinson's disease, Alzheimer's disease, and multiple sclerosis. ${ }^{110-113}$ Animal studies have also demonstrated persistence of inflammation for at least one year after the initial insult. ${ }^{114-116}$ This suggests that the window of opportunity for therapeutic intervention may be much longer than is usually considered.

Impairment of the BBB appears to facilitate increased accumulation of the dendrimer in the brain. Although the neonatal BBB has been shown to be well-developed, similar to that in the adult brain, the presence of an injury can result in impairment of the BBB. The degree of leakage through the $\mathrm{BBB}$ can be variable, and may depend on the type of disease, 
Table I Preclinical studies using nanoparticles for therapeutic delivery for neuroinflammation and neurodegeneration

\begin{tabular}{|c|c|c|c|}
\hline Disease model & Nanoparticle platform & Administration route & Main conclusion \\
\hline \multirow[t]{5}{*}{ Alzheimer's } & Curcumin delivery & Intraperitoneal & NanoCurc can ameliorate reactive oxygen species-mediated damage ${ }^{67}$ \\
\hline & by polymeric nanoparticle & Oral & $\begin{array}{l}\text { Oral administration resulted in significant improvements in working } \\
\text { and cue memory }{ }^{88}\end{array}$ \\
\hline & $\begin{array}{l}\text { Piperine delivery by solid } \\
\text { lipid nanoparticles }\end{array}$ & Intraperitoneal & $\begin{array}{l}\text { SLN coated with P80 shows therapeutic effect through reduced } \\
\text { oxidative stress }{ }^{69}\end{array}$ \\
\hline & $\begin{array}{l}\text { Indomethacin delivery } \\
\text { by solid lipid nanoparticles }\end{array}$ & Intraperitoneal & SLN attenuated cell death and suppressed microglial activation ${ }^{65}$ \\
\hline & $\begin{array}{l}\text { Carbon nanotube delivery } \\
\text { of acetylcholine }\end{array}$ & Gastrogavage & $\begin{array}{l}\text { Therapeutic effect due to delivery of acetylcholine into neuronal } \\
\text { lysosomes }{ }^{71}\end{array}$ \\
\hline \multirow[t]{6}{*}{ Parkinson's } & $\begin{array}{l}\text { NGF delivery by P80 } \\
\text { coated PBCA nanoparticle }\end{array}$ & Intravenous & Reduction of oligokinesia, rigidity, and tremor ${ }^{72}$ \\
\hline & Urocortin delivery & Intravenous & Attenuation of striatum lesion ${ }^{73}$ \\
\hline & by PLGA-PEG & Intranasal & Functional and behavioral recovery obtained ${ }^{74}$ \\
\hline & $\begin{array}{l}\text { Apomorphine delivery } \\
\text { by solid lipid nanoparticles }\end{array}$ & Oral & Better therapeutic efficacy for behavioral recovery ${ }^{75}$ \\
\hline & $\begin{array}{l}\text { GDNF delivery } \\
\text { by PEGylated dendrimers }\end{array}$ & Intravenous & $\begin{array}{l}\text { Improved locomotor activity, reduction of neuronal loss } \\
\text { and enhanced neurotransmitter level }\left.\right|^{76,77}\end{array}$ \\
\hline & $\begin{array}{l}\text { GDNF delivery } \\
\text { by immunoliposomes }\end{array}$ & Intravenous & Partial behavioral recovery and rescue of striatal tract ${ }^{78}$ \\
\hline $\begin{array}{l}\text { Multiple sclerosis } \\
\text { or ALS }\end{array}$ & Fullerenes & Intraperitoneal & Reduction of MS progression by decrease in axonal and myelin loss ${ }^{79}$ \\
\hline Cerebral palsy & $\begin{array}{l}\text { NAC delivery } \\
\text { by PAMAM dendrimers }\end{array}$ & Intravenous & $\begin{array}{l}\text { NAC conjugated dendrimers suppress neuroinflammation and } \\
\text { improve motor function in CP rabbits }{ }^{42}\end{array}$ \\
\hline \multirow[t]{8}{*}{ Ischemia/stroke } & $\begin{array}{l}\text { Hemoglobin delivery } \\
\text { by liposome }\end{array}$ & Intraparenchymal & Suppression of infarct areas in rats with stroke ${ }^{80,81}$ \\
\hline & $\begin{array}{l}\text { VEGF delivery by } \\
\text { immunoliposomes }\end{array}$ & Intravenous & Decreased infarct volume and promotion of neurovascularization ${ }^{82}$ \\
\hline & Carbon nanotubes & Intraventricular & $\begin{array}{l}\text { Protection of neurons and } \\
\text { enhanced motor neuron function }{ }^{83}\end{array}$ \\
\hline & $\begin{array}{l}\text { siRNA delivery } \\
\text { by PAMAM dendrimers }\end{array}$ & Intraparenchymal & $\begin{array}{l}\text { Infarct formation suppression in post-ischemic brain with } \\
\text { pretreatment }^{84}\end{array}$ \\
\hline & Chitosan PEG-nanospheres & Intravenous & $\begin{array}{l}\text { Neuroprotection by delivery of anti-caspase peptide in stroke with } \\
\text { pre-treatment and immediately after injury }{ }^{85}\end{array}$ \\
\hline & Fullerenes & $\begin{array}{l}\text { Intravenous and } \\
\text { intraventricular }\end{array}$ & $\begin{array}{l}\text { Suppression of cerebral infarction volume and attenuation of } \\
\text { oxidative injuries }{ }^{86-88}\end{array}$ \\
\hline & Nitroxyl radical delivery & Intracarotid & Reduced infarct volume by $65 \%$ \\
\hline & by core-shell micelles & & Reduced superoxide anions in neuronal cells and infarction volume $\mathrm{e}^{84,85}$ \\
\hline Traumatic & PEGylated silica nanoparticles & Intravenous & Spinal cord conduction recovered ${ }^{91}$ \\
\hline brain injury & $\begin{array}{l}\text { Carbon nanotube } \\
\text { functionalized with PEG }\end{array}$ & Intraspinal & Some improvement in hind-limb locomotor function ${ }^{92}$ \\
\hline Epilepsy & $\begin{array}{l}\text { Phenytoin delivery } \\
\text { by liposomes }\end{array}$ & Intravenous & Reduced penicillin induced epileptic activity ${ }^{93}$ \\
\hline
\end{tabular}

Abbreviations: NanoCurc, curcumin nanoparticles; siRNA, small interfering ribonucleic acid; SLN, solid lipid nanoparticles; NGF, nerve growth factor; P80, polysorbate-80; PBCA, poly(butyl cyanoacrylate); PLGA-PEG, poly(lactic-co-glycolic acid-poly(ethylene-glycol); GDNF, glial cell line-derived neurotrophic factor; MS, multiple sclerosis; ALS, amyotrophic lateral sclerosis; PAMAM, polyamidoamine; NAC, N-acetyl cysteine; CP, cerebral palsy; VEGF, vascular endothelial growth factor; PEG, poly(ethylene glycol).

the developmental age and timing from the insult. ${ }^{117}$ Since ongoing inflammation is often associated with increased BBB permeability resulting from formation of matrix metalloproteinases, ${ }^{118}$ this impairment may also persist after the initial insult. In the presence of neuroinflammation or injury resulting in BBB impairment, leakage of intravenously administered gadolinium contrast in the brain parenchyma has been described in patients and in animal models. ${ }^{119,120}$ Figure 4 demonstrates diffuse gadolinium enhancement in the brain parenchyma in an infant at 8 days after a hypoxic ischemic insult, indicating that the BBB impairment may persist for days or even weeks after the original insult, potentially extending the therapeutic window. Microglial cells can have both protective and harmful roles; hence, the time point at which microglial activation is suppressed may be crucial for dictating the response. ${ }^{121}$ It is possible that the initial microglial response may involve pro- and anti-inflammation, with a peak proinflammatory response that occurs later. ${ }^{122}$ Our studies suggest that attenuation of the microglial response in the newborn rabbit with maternal inflammation-induced 
Table 2 Clinical studies using nanoparticles for therapeutic delivery in the CNS

\begin{tabular}{|c|c|c|c|}
\hline Nanoparticle platform & Disease & Administration route & Main conclusion \\
\hline $\begin{array}{l}\text { Magnetic iron-oxide } \\
\text { nanoparticles }\end{array}$ & $\begin{array}{l}\text { Recurrent glioblastoma } \\
\text { multiforme }\end{array}$ & Intratumoral & $\begin{array}{l}\text { Combined with fractionated stereotactic radiotherapy, magnetic } \\
\text { NPs are safe and effective, leading to longer overall survival }{ }^{94}\end{array}$ \\
\hline \multirow[t]{2}{*}{$\begin{array}{l}\text { Liposomal } \\
\text { doxorubicin }\end{array}$} & $\begin{array}{l}\text { Glioblastoma, primary } \\
\text { or recurrent }\end{array}$ & Intravenous & $\begin{array}{l}\text { The addition of PEG-dox with prolonged TMZ did not result in } \\
\text { meaningful improvement of the patient's outcome }{ }^{95,96}\end{array}$ \\
\hline & Brain metastases & Intravenous & $\begin{array}{l}\text { TMZ/pegylated liposomal doxorubicin regimen was well tolerated } \\
\text { with an encouraging activity in brain metastases from solid tumors }\end{array}$ \\
\hline \multirow[t]{3}{*}{$\begin{array}{l}\text { Liposomal } \\
\text { cytarabine }\end{array}$} & Primary CNS tumors & Lumbar injection & $\begin{array}{l}\text { Liposomal cytarabine well tolerated and efficacious in this patient } \\
\text { group }{ }^{98}\end{array}$ \\
\hline & $\begin{array}{l}\text { Recurrent brain } \\
\text { tumors }\end{array}$ & Intrathecal & $\begin{array}{l}\text { Intrathecal liposomal cytarabine was generally well tolerated, } \\
\text { but should be used cautiously and only with dexamethasone } \\
\text { prophylaxis in extensively pretreated patients } 99,100\end{array}$ \\
\hline & Embryonal neoplasms & Intrathecal & $\begin{array}{l}\text { Liposomal cytarabine may play a role in improving response and } \\
\text { outcomes with low toxicity in patients with otherwise fatal CNS } \\
\text { embryonal tumors }{ }^{101}\end{array}$ \\
\hline $\begin{array}{l}\text { Cationic IL-12 } \\
\text { liposomes }\end{array}$ & Malignant glioma & Intratumoral & $\begin{array}{l}\text { Trial stopped due to additional pre-clinical studies showing } \\
\text { neurotoxicity }{ }^{102,103}\end{array}$ \\
\hline $\begin{array}{l}\text { Cationic IFN- } \beta \\
\text { liposomes }\end{array}$ & Malignant glioma & Intratumoral & $\begin{array}{l}\text { Demonstration of the feasibility and safety of IFN- } \beta \text { gene therapy } \\
\text { for MG }{ }^{104}\end{array}$ \\
\hline
\end{tabular}

Abbreviations: CNS, central nervous system; NP, nanoparticle; PEG-dox, poly(ethylene glycol)-doxorubicin; TMZ, temozolomide; MG, malignant glioma; IL, interleukin; IFN, interferon.

$\mathrm{CP}$, at 3 days after the injury, leads to improved neurological outcomes in the short term. ${ }^{42}$ In that study, the therapeutic intervention occurred later in the postnatal period, after the injury had occurred, at time points when there was ongoing inflammation. Nanoparticle uptake and delivery of therapeutic agents into the cells may also be influenced by the microglial phenotype and function during different stages of the disease. All these features will have to be carefully considered when designing therapies for brain injury in $\mathrm{CP}$. We have previously shown that the hydroxyl terminated dendrimers are taken up intracellularly by active pinocytosis. ${ }^{123}$ It is possible that activated microglia have a greater phagocytic and/or pinocytic capacity that allows them to selectively take up the dendrimers. Future studies to elucidate the specific processes involved
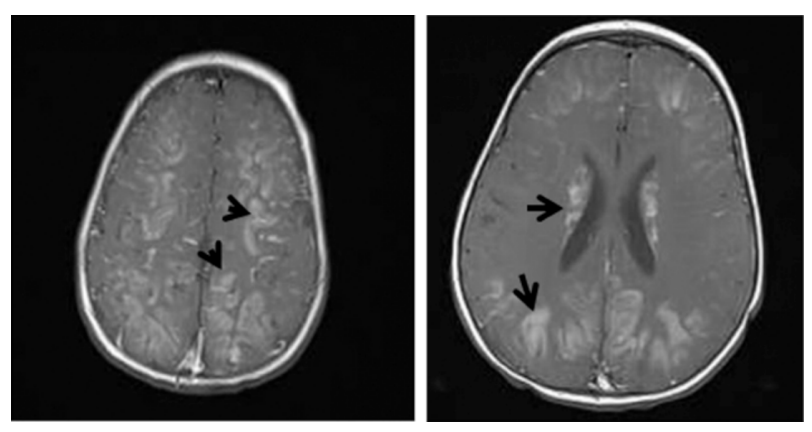

Figure 4 MRI with gadolinium in an infant with hypoxic ischemic encephalopathy 8 days after the injury.

Notes: Postcontrast TI images demonstrate diffuse leakage of gadolinium in the brain parenchyma (arrows) that is most prominent in the basal ganglia around the ventricles and in the frontal, parietal and occipital cortex. This indicates significant impairment of the blood-brain barrier that is present several days after the injury. in dendrimer uptake by the activated microglia would be crucial in further optimizing the drug delivery nanodevice.

\section{Biosafety and toxicity studies for nanoparticle platforms}

As the therapeutic field of nanotechnology steadily advances, a detailed evaluation of nanoparticles in vivo is essential to address the issues of biosafety and toxicity of these particles. ${ }^{124,125}$ Multiwalled carbon nanotubes injected into pregnant mice have been shown to result in teratogenic effects in the embryo, ${ }^{126}$ and cationic amine terminal G4 dendrimers were found to be toxic in developing zebra fish embryos. ${ }^{127}$ To maintain a balance between maximum therapeutic efficacy and reduced toxicity in the developing brain, it is essential to determine the dose, type of nanoparticle, and route of administration. We have shown that administration of $550 \mathrm{mg} / \mathrm{kg}$ of G4OH PAMAM dendrimer, which is 10 times the dose used in the efficacy studies, did not demonstrate any toxic effects in newborn rabbits. ${ }^{42}$ It is likely that the presence of the neutral -OH groups on the dendrimer surface may be responsible for the increased safety profile in these animals. However, further studies in larger animals would be important to establish the biosafety profile of the hydroxylterminated dendrimers for prenatal and postnatal treatment.

\section{Future directions}

An ideal therapeutic strategy would not only involve suppression of inflammation and injury but also promote regeneration and repair. Because several mechanisms such as inflammation, excitotoxicity, and oxidative injury con- 


\section{Maternal therapy}

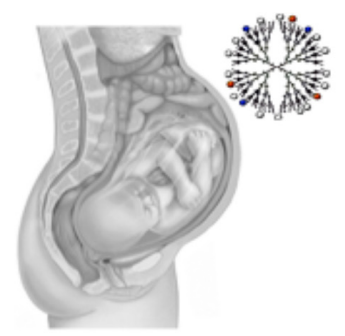

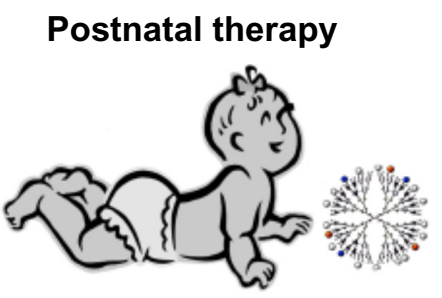

Decrease inflammation and excitotoxicity

Prenatal therapy (dendrimer injected into amniotic fluid)

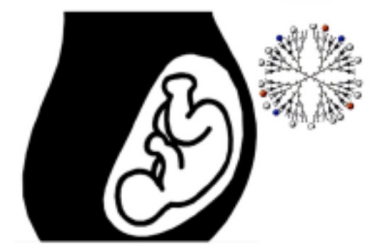

Decrease fetal immune response

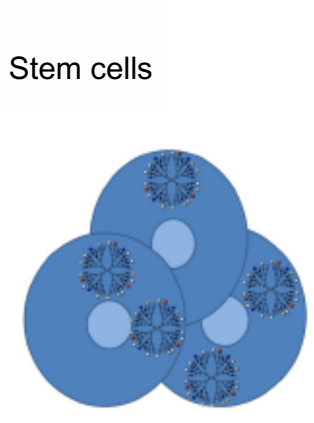

Trophic factors
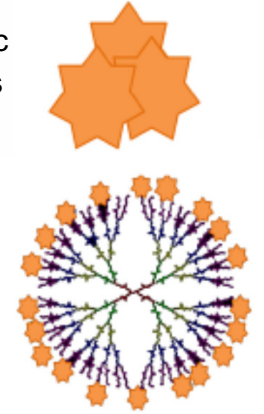
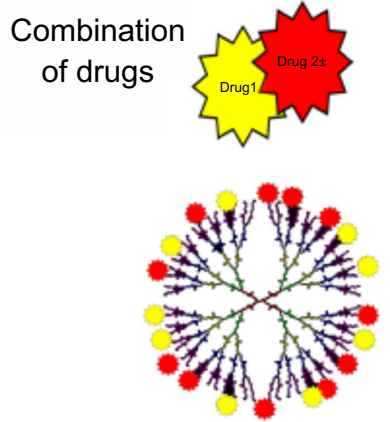

Figure 5 Potential future nanotherapeutic approaches in cerebral palsy.

Notes: Dendrimer-based drug delivery to pregnant mothers with infection/inflammation may reduce inflammatory response in the mother and the fetus. Prenatal therapies may involve systemic treatment of the mother to modulate the maternal immune response and/or treatment of the fetus by intra-amniotic administration of the nanodevices. Postnatal therapies would involve treatment of ongoing injury after birth. Therapies may potentially involve use of stem cells in combination with drugs or after modification by nanoparticles to promote differentiation; delivery of trophic and growth factors, or delivery of combination therapies using nanoparticles.

tribute to the brain injury, combination therapies delivered to the brain that target multiple pathways would provide the maximum benefit. When these therapies are combined with approaches to promote regeneration, such as delivery of growth factors and stem cells, it may be possible to achieve normal brain development and functioning for a disorder that currently has no therapies available. Presence of risk factors for $\mathrm{CP}$, such as chorioamnionitis, maternal fever, perinatal asphyxia, intraventricular hemorrhage, persistence of serum inflammatory biomarkers after birth, and neonatal white matter abnormalities ${ }^{128-133}$ that are well characterized in several epidemiological studies, will help in the early identification of infants who would benefit from such therapies soon after birth or even in utero. Prenatal therapy that is directed toward regulating the maternal inflammatory response and/or fetal inflammation may also provide therapeutic strategies that can prevent brain injury in at-risk patients (Figure 5). We have previously shown that G4-OH PAMAM dendrimers do not cross the normal human placenta. ${ }^{134}$ This feature could be exploited for tailoring the treatment to the maternal and fetal compartments. We would anticipate that systemic therapies administered to the mother would remain in the maternal compartment and could be leveraged to modulate the maternal immune response, hence indirectly changing the fetal immune response. Similarly, administration of the dendrimer nanodevices in the amniotic fluid can be a potential route of prenatal treatment for prevention of perinatal brain injury. Postnatal therapies can be further refined by a mul- 
tipronged approach that would attenuate several pathways involved in inflammation, through combination therapies and by coadministering trophic factors and/or stem cells that would promote repair and regeneration. Several in vitro studies have demonstrated the feasibility of modifying stem cells with nanoparticles that include dendrimers. ${ }^{135-138}$ Stem cells that have been modified to promote differentiation that is individually tailored for the type of injury has the potential to aid treatment of older patients with cerebral palsy.

\section{Acknowledgment}

The authors thank Dr Amar Jyoti for the astrocyte images.

\section{Disclosure}

The authors report no conflicts of interest in this work. This work was supported in part by R01 HD069562, NICHD, $\mathrm{NIH}$.

\section{References}

1. Raju TN. Historical perspectives on the etiology of cerebral palsy. Clin Perinatol. 2006;33(2):233-250.

2. Koman LA, Smith BP, Shilt JS. Cerebral palsy. Lancet. 2004;363(9421): 1619-1631.

3. Andiman SE, Haynes RL, Trachtenberg FL, et al. The cerebral cortex overlying periventricular leukomalacia: analysis of pyramidal neurons. Brain Pathol. 2010;20(4):803-814.

4. Pierson CR, Folkerth RD, Billiards SS, et al. Gray matter injury associated with periventricular leukomalacia in the premature infant. Acta Neuropathol. 2007;114(6):619-631.

5. Ligam P, Haynes RL, Folkerth RD, et al. Thalamic damage in periventricular leukomalacia: novel pathologic observations relevant to cognitive deficits in survivors of prematurity. Pediatr Res. 2009;65(5):524-529.

6. Banker BQ, Larroche JC. Periventricular leukomalacia of infancy. A form of neonatal anoxic encephalopathy. Arch Neurol. 1962;7:386-410.

7. Bax M, Goldstein M, Rosenbaum P, et al. Proposed definition and classification of cerebral palsy, Apr 2005. Dev Med Child Neurol. 2005;47(8):571-576.

8. Kuban KC, Leviton A. Cerebral palsy. N Engl J Med. 1994;330(3): $188-195$.

9. Centers for Disease Control and Prevention (CDC). Economic costs associated with mental retardation, cerebral palsy, hearing loss, and vision impairment - United States, 2003. Morb Mortal Wkly Rep. 53(3):57-59.

10. Arneson CL, Durkin MS, Benedict RE, et al. Prevalence of cerebral palsy: Autism and Developmental Disabilities Monitoring Network, three sites, United States, 2004. Disabil Health J. 2009;2(1):45-48.

11. Cummins SK, Nelson KB, Grether JK, et al. Cerebral palsy in four northern California counties, births 1983 through 1985. J Pediatr. 1993;123(2):230-237.

12. Himmelmann K, Hagberg G, Beckung E, et al. The changing panorama of cerebral palsy in Sweden. IX. Prevalence and origin in the birth-year period 1995-1998. Acta Paediatr. 2005;94(3):287-294.

13. Johnston MV, Fatemi A, Wilson MA, et al. Treatment advances in neonatal neuroprotection and neurointensive care. Lancet Neurol. 2011;10(4):372-382.

14. Stoll BJ, Hansen NI, Bell EF, et al; Eunice Kennedy Shriver National Institute of Child Health and Human Development Neonatal Research Network. Neonatal outcomes of extremely preterm infants from the NICHD Neonatal Research Network. Pediatrics. 2010;126(3): 443-456.
15. Gargus RA, Vohr BR, Tyson JE, et al. Unimpaired outcomes for extremely low birth weight infants at 18 to 22 months. Pediatrics. 2009;124(1):112-121.

16. Eicher DJ, Wagner CL, Katikaneni LP, et al. Moderate hypothermia in neonatal encephalopathy: safety outcomes. Pediatr Neurol. 2005;32(1):18-24.

17. Pakula AT, Van Naarden Braun K, et al. Cerebral palsy: classification and epidemiology. Phys Med Rehabil Clin N Am. 2009;20(3):425-452.

18. Wu YW, Colford JM Jr. Chorioamnionitis as a risk factor for cerebral palsy: a meta-analysis. JAMA. 2000;284(11):1417-1424.

19. Romero R, Espinoza J, Goncalves LF, et al. The role of inflammation and infection in preterm birth. Sem Reprod Med. Jan 2007;25(1):21-39.

20. Schaefer GB. Genetics considerations in cerebral palsy. Semin Pediatr Neurol. 2008;15(1):21-26.

21. Haynes RL, Baud O, Li J, et al. Oxidative and nitrative injury in periventricular leukomalacia: a review. Brain Pathol. 2005;15(3):225-233.

22. Billiards SS, Haynes RL, Folkerth RD, et al. Development of microglia in the cerebral white matter of the human fetus and infant. $J$ Comp Neuro. 2006;497(2):199-208.

23. Masuda-Nakagawa LM, Muller KJ, Nicholls JG. Axonal sprouting and laminin appearance after destruction of glial sheaths. Proc Natl Acad Sci US A. 1993;90(11):4966-4970.

24. Aguzzi A, Barres BA, Bennett ML. Microglia: scapegoat, saboteur, or something else? Science. 2013:339:156-160.

25. Tabas I, Glass CK. Anti-inflammatory therapy in chronic disease: challenges and opportunities. Science. 2013;339:166-172.

26. Hagberg H, Gressens P, Mallard C. Inflammation during fetal and neonatal life: implications for neurologic and neuropsychiatric disease in children and adults. Ann Neurol. 2012;71(4):444-457.

27. McAdams RM, Juul SE. The role of cytokines and inflammatory cells in perinatal brain injury. Neuro Res Int. 2012;2012:561494.

28. Czeh M, Gressens P, Kaindl AM. The yin and yang of microglia. Dev Neurosci. 2011;33(3-4):199-209.

29. Faustino JV, Wang X, Johnson CE, et al. Microglial cells contribute to endogenous brain defenses after acute neonatal focal stroke. J Neurosci. 2011;31:12992-13001.

30. Maragakis NJ, Rothstein JD. Mechanisms of Disease: astrocytes in neurodegenerative disease. Nat Clin Prac Neurol. 2006;2(12): 679-689.

31. Rock RB, Gekker G, Hu S, et al. Role of microglia in central nervous system infections. Clin Microbiol Rev. 2004;17(4):942-964.

32. Cunningham CL, Martínez-Cerdeño V, Noctor SC. Microglia regulate the number of neural precursor cells in the developing cerebral cortex. J Neurosci. 2013;33(10):4216-4233.

33. Falahati S, Breu M, Waickman AT, et al. Ischemia-induced neuroinflammation is associated with disrupted development of oligodendrocyte progenitors in a model of periventricular leukomalacia. Dev Neurosci. 2013;35(2-3):182-196.

34. Buser JR, Maire J, Riddle A, et al. Arrested preoligodendrocyte maturation contributes to myelination failure in premature infants. Ann Neuro. 2012;71(1):93-109.

35. Gilles FH, Murphy SF. Perinatal telencephalic leucoencephalopathy. J Neurol Neurosurg Psychiatr. 1969;32(5):404-413.

36. Mallard C, Welin AK, Peebles D, et al. White matter injury following systemic endotoxemia or asphyxia in the fetal sheep. Neurochem Res. 2003;28(2):215-223.

37. Saadani-Makki F, Kannan S, Makki M, et al. Intrauterine endotoxin administration leads to white matter diffusivity changes in newborn rabbits. J Child Neurol. 2009;24(9):1179-1189.

38. Kannan S, Saadani-Makki F, Balakrishnan B, et al. Magnitude of [(11)C] PK11195 binding is related to severity of motor deficits in a rabbit model of cerebral palsy induced by intrauterine endotoxin exposure. Dev Neurosci. 2011;33(3-4):231-240.

39. Iezzi R, Guru BR, Glybina IV, et al. Dendrimer-based targeted intravitreal therapy for sustained attenuation of neuroinflammation in retinal degeneration. Biomaterials. 2012;33(3):979-988. 
40. Menjoge AR, Navath RS, Asad A, et al. Transport and biodistribution of dendrimers across human fetal membranes: implications for intravaginal administration of dendrimer-drug conjugates. Biomaterials. 2010;31(18):5007-5021.

41. Dai H, Navath RS, Balakrishnan B, et al. Intrinsic targeting of inflammatory cells in the brain by polyamidoamine dendrimers upon subarachnoid administration. Nanomedicine (Lond). 2010;5(9): 1317-1329.

42. Kannan S, Dai H, Navath RS, et al. Dendrimer-based postnatal therapy for neuroinflammation and cerebral palsy in a rabbit model. Science Transl Med. 2012;4(130):130ra146.

43. Wohlfart S, Gelperina S, Kreuter J. Transport of drugs across the blood-brain barrier by nanoparticles. J Control Release. 2012;161(2): 264-273.

44. Nance EA, Woodworth GF, Sailor KA, et al. A dense poly(ethylene glycol) coating improves penetration of large polymeric nanoparticles within brain tissue. Sci Transl Med. 2012;4(149):149ra119.

45. Hayder M, Poupot M, Baron M, et al. A phosphorus-based dendrimer targets inflammation and osteoclastogenesis in experimental arthritis. Sci Transl Med. 2011;3(81):81ra35.

46. Lee CC, MacKay JA, Frechet JM, et al. Designing dendrimers for biological applications. Nat Biotechnol. 2005;23(12): 1517-1526.

47. Menjoge AR KR, Tomalia DA. Dendrimer-based drug and imaging agent conjugates: design considerations for nanomedical applications. Drug Discov Today. 2010;15(5-6):171-185.

48. Xu Q, Kambhampati SP, Kannan RM. Nanotechnology approaches for ocular drug delivery. Middle East Afr J Ophthalmol. 2013;20(1): 26-37.

49. Tripathi PK, Khopade AJ, Nagaich S, et al. Dendrimer grafts for delivery of 5-fluorouracil. Pharmazie. 2002;57(4):261-264.

50. Chandrasekar D, Sistla R, Ahmad FJ, et al. The development of folatePAMAM dendrimer conjugates for targeted delivery of anti-arthritic drugs and their pharmacokinetics and biodistribution in arthritic rats Biomaterials. 2007;28(3):504-512.

51. Kukowska-Latallo JF, Candido KA, Cao Z, et al. Nanoparticle targeting of anticancer drug improves therapeutic response in animal model of human epithelial cancer. Cancer Res. 2005;65(12):5317-5324.

52. Taite LJ, West JL. Poly(ethylene glycol)-lysine dendrimers for targeted delivery of nitric oxide. J Biomater Sci Polymer Ed. 2006;17(10): 1159-1172.

53. Leviton A, Kuban K, O'Shea TM, et al. The relationship between early concentrations of 25 blood proteins and cerebral white matter injury in preterm newborns: the ELGAN study. J Pediatr. 2011;158(6):897-903. e1-e5.

54. Kannan S, Chugani HT. Applications of positron emission tomography in the newborn nursery. Semin Perinatol. 2010;34(1):39-45.

55. Tan S. A baby step for nano. Sci Transl Med. 2012;4(130):130fs8.

56. Brok J, Buckley N, Gluud C. Interventions for paracetamol (acetaminophen) overdose. Cochrane Database Syst Rev. 2006(2): CD003328.

57. Indiana University School of Medicine. A Study of Oral N-Acetylcysteine in Children With Autism Spectrum Disorders. Available from: http://clinicaltrials.gov/show/NCT00453180. NLM identifier: NCT00453180. Accessed August 15, 2013.

58. Stanford University. A Study of N-Acetyl Cysteine in Children With Autism. Available from: http://clinicaltrials.gov/ct2/show/NCT00627 705? term=NCT00627705\&rank=1. NLM identifier: NCT00627705 Accessed August 15, 2013.

59. Yale University. N-acetylcysteine in Intra-amniotic Infection/Inflammation. Available from: http://clinicaltrials.gov/ct2/show/NCT00397735. NLM identifier: NCT00397735. Accessed August 15, 2013.

60. Medical University of South Carolina. Safety of N-acetylcysteine in Maternal Chorioamnionitis (NAC in Chorio). Available from: http://clinicaltrials.gov/ct2/show/NCT00724594. NLM identifier: NCT00724594. Accessed August 15, 2013.
61. University of Massachusetts, Worcester. A Clinical Trial of a Vitamin Nutriceutical Formulation for Alzheimer's Disease. Available from: http:/clinicaltrials.gov/ct2/show/NCT01320527. NLM identifier: NCT01320527. Accessed August 15, 2013.

62. Olsson B, Johansson M, Gabrielsson J, et al. Pharmacokinetics and bioavailability of reduced and oxidized N-acetylcysteine. Eur J Clin Pharmacol. 1988;34(1):77-82.

63. Janaky R, Varga V, Hermann A, Saransaari P, Oja SS. Mechanisms of L-cysteine neurotoxicity. Neurochem Res. 2000;25(9-10): 1397-1405.

64. Albertazzi L, Gherardini L, Brondi M, et al. In vivo distribution and toxicity of PAMAM dendrimers in the central nervous system depend on their surface chemistry. Mol Pharm. 2013;10(1):249-260.

65. Nunes A, Al-Jamal KT, Kostarelos K. Therapeutics, imaging and toxicity of nanomaterials in the central nervous system. J Control Release. 2012;161(2):290-306.

66. Wong HL, Wu XY, Bendayan R. Nanotechnological advances for the delivery of CNS therapeutics. Adv Drug Deliv Rev. 2012;64(7): 686-700.

67. Ray B, Bisht S, Maitra A, Lahiri DK. Neuroprotective and neurorescue effects of a novel polymeric nanoparticle formulation of curcumin (NanoCurc) in the neuronal cell culture and animal model: implications for Alzheimer's disease. J Alzheimers Dis. 2011;23(1): 61-77.

68. Cheng KK, Yeung CF, Ho SW, et al. Highly stabilized curcumin nanoparticles tested in an in vitro blood-brain barrier model and in Alzheimer's disease Tg2576 mice. AAPS J. 2013;15(2):324-326.

69. Yusuf M, Khan M, Khan RA, et al. Preparation, characterization, in vivo and biochemical evaluation of brain targeted Piperine solid lipid nanoparticles in an experimentally induced Alzheimer's disease model. J Drug Target. Epub December 11, 2012.

70. Bernardi A, Frozza RL, Meneghetti A, et al. Indomethacin-loaded lipid-core nanocapsules reduce the damage triggered by Abeta 1-42 in Alzheimer's disease models. Int J Nanomed. 2012;7:4927-4942.

71. Yang Z, Zhang Y, Yang Y, et al. Pharmacological and toxicological target organelles and safe use of single-walled carbon nanotubes as drug carriers in treating Alzheimer disease. Nanomedicine. 2010;6(3): $427-441$.

72. Kurakhmaeva KB, Djindjikhashvili IA, Petrov VE, et al. Brain targeting of nerve growth factor using poly(butyl cyanoacrylate) nanoparticles. J Drug Target. 2009;17(8):564-574.

73. Hu K, Shi Y, Jiang W, Han J, Huang S, Jiang X. Lactoferrin conjugated PEG-PLGA nanoparticles for brain delivery: preparation, characterization and efficacy in Parkinson's disease. Int J Pharma. 2011;415(1-2): 273-283.

74. Wen Z, Yan Z, Hu K, et al. Odorranalectin-conjugated nanoparticles: preparation, brain delivery and pharmacodynamic study on Parkinson's disease following intranasal administration. $J$ Control Release. 2011;151(2):131-138.

75. Tsai MJ, Huang YB, Wu PC, et al. Oral apomorphine delivery from solid lipid nanoparticles with different monostearate emulsifiers: pharmacokinetic and behavioral evaluations. J Pharma Sci. 2011;100(2): $547-557$.

76. Huang R, Han L, Li J, et al. Neuroprotection in a 6-hydroxydopaminelesioned Parkinson model using lactoferrin-modified nanoparticles. J Gene Med. 2009;11(9):754-763.

77. Huang R, Ke W, Han L, et al. Lactoferrin-modified nanoparticles could mediate efficient gene delivery to the brain in vivo. Brain Res Bull. 2010;81(6):600-604.

78. Xia CF, Boado RJ, Zhang Y, et al. Intravenous glial-derived neurotrophic factor gene therapy of experimental Parkinson's disease with Trojan horse liposomes and a tyrosine hydroxylase promoter. J Gene Med. 2008;10(3):306-315.

79. Basso AS, Frenkel D, Quintana FJ, et al. Reversal of axonal loss and disability in a mouse model of progressive multiple sclerosis. J Clin Invest. 2008;118(4):1532-1543. 
80. Kawaguchi AT, Kurita D, Furuya H, et al. Liposome-encapsulated hemoglobin alleviates brain edema after permanent occlusion of the middle cerebral artery in rats. Artif Organs. 2009;33(2):153-158.

81. Kawaguchi AT, Fukumoto D, Haida M, et al. Liposome-encapsulated hemoglobin reduces the size of cerebral infarction in the rat: evaluation with photochemically induced thrombosis of the middle cerebral artery. Stroke. 2007;38(5):1626-1632.

82. Zhao H, Bao XJ, Wang RZ, et al. Postacute ischemia vascular endothelial growth factor transfer by transferrin-targeted liposomes attenuates ischemic brain injury after experimental stroke in rats. Hum Gene Ther. 2011;22(2):207-215.

83. Lee HJ, Park J, Yoon OJ, et al. Amine-modified single-walled carbon nanotubes protect neurons from injury in a rat stroke model. Nat Nanotechnol. 2011;6(2):121-125.

84. Karatas H, Aktas Y, Gursoy-OzdemirY, et al. A nanomedicine transports a peptide caspase-3 inhibitor across the blood-brain barrier and provides neuroprotection. J Neurosci. 2009;29(44):13761-13769.

85. Kim ID, Lim CM, Kim JB, et al. Neuroprotection by biodegradable PAMAM ester (e-PAM-R)-mediated HMGB1 siRNA delivery in primary cortical cultures and in the postischemic brain. J Control Release. 2010;142(3):422-430.

86. Huang SS, Tsai SK, Chih CL, et al. Neuroprotective effect of hexasulfobutylated $\mathrm{C} 60$ on rats subjected to focal cerebral ischemia. Free Radic Biol Med. 2001;30(6):643-649.

87. Yang DY, Wang MF, Chen IL, et al. Systemic administration of a watersoluble hexasulfonated $\mathrm{C}(60)$ (FC(4)S) reduces cerebral ischemia-induced infarct volume in gerbils. Neurosci Lett. 2001;311(2): 121-124.

88. Lin AM, Fang SF, Lin SZ, et al. Local carboxyfullerene protects cortical infarction in rat brain. Neurosci Res. 2002;43(4):317-321.

89. Reddy MK, Labhasetwar V. Nanoparticle-mediated delivery of superoxide dismutase to the brain: an effective strategy to reduce ischemia-reperfusion injury. FASEB J. 2009;23(5):1384-1395.

90. Marushima A, Suzuki K, Nagasaki Y, et al. Newly synthesized radical-containing nanoparticles enhance neuroprotection after cerebral ischemia-reperfusion injury. Neurosurgery. 2011;68(5):1418-1425; discussion 1425-1416.

91. Cho Y, Shi R, Borgens R, Ivanisevic A. Repairing the damaged spinal cord and brain with nanomedicine. Small. 2008;4(10):1676-1681.

92. Roman JA, Niedzielko TL, Haddon RC, et al. Single-walled carbon nanotubes chemically functionalized with polyethylene glycol promote tissue repair in a rat model of spinal cord injury. J Neurotrauma. 2011;28(11):2349-2362.

93. Mori N, Kurokouchi A, Osonoe K, et al. Liposome-entrapped phenytoin locally suppresses amygdaloid epileptogenic focus created by db-cAMP/ EDTA in rats. Brain Res. 1995;703(1-2):184-190.

94. Maier-Hauff K, Ulrich F, Nestler D, et al. Efficacy and safety of intratumoral thermotherapy using magnetic iron-oxide nanoparticles combined with external beam radiotherapy on patients with recurrent glioblastoma multiforme. J Neurooncol. 2011;103(2):317-324.

95. Beier CP, Schmid C, Gorlia T, et al. RNOP-09: pegylated liposomal doxorubicine and prolonged temozolomide in addition to radiotherapy in newly diagnosed glioblastoma - a phase II study. BMC Cancer. 2009;9:308

96. Hau P, Fabel K, Baumgart U, et al. Pegylated liposomal doxorubicinefficacy in patients with recurrent high-grade glioma. Cancer. 2004; 100(6):1199-1207.

97. Caraglia M, Addeo R, Costanzo R, et al. Phase II study of temozolomide plus pegylated liposomal doxorubicin in the treatment of brain metastases from solid tumours. Cancer Chemother Pharmacol. J2006;57(1):34-39.

98. Navajas A, Lassaletta A, Morales A, et al. Efficacy and safety of liposomal cytarabine in children with primary CNS tumours with leptomeningeal involvement. Clinical Trans Oncol. 2012;14(4): 280-286.

99. Benesch M, Siegler N, Hoff Kv, et al. Safety and toxicity of intrathecal liposomal cytarabine (Depocyte) in children and adolescents with recurrent or refractory brain tumors: a multi-institutional retrospective study. Anticancer Drugs. 2009;20(9):794-799.
100. Lassaletta A, Lopez-Ibor B, Mateos E, et al. Intrathecal liposomal cytarabine in children under 4 years with malignant brain tumors. J Neurooncol. 2009;95(1):65-69.

101. Partap S, Murphy PA, Vogel H, et al. Liposomal cytarabine for central nervous system embryonal tumors in children and young adults. J Neurooncol. 2011;103(3):561-566.

102. Ren H, Boulikas T, Lundstrom K, et al. Immunogene therapy of recurrent glioblastoma multiforme with a liposomally encapsulated replication-incompetent Semliki forest virus vector carrying the human interleukin-12 gene - a phase I/II clinical protocol. J Neurooncol. 2003;64(1-2):147-154.

103. Graham A, Walker R, Baird P, et al. CNS gene therapy applications of the Semliki Forest virus 1 vector are limited by neurotoxicity. Mol Ther. 2006;13(3):631-635.

104. Yoshida J, Mizuno M, Fujii M, et al. Human gene therapy for malignant gliomas (glioblastoma multiforme and anaplastic astrocytoma) by in vivo transduction with human interferon beta gene using cationic liposomes. Hum Gene Ther. 2004;15(1):77-86.

105. Brochu ME, Girard S, Lavoie K, Sébire G. Developmental regulation of the neuroinflammatory responses to LPS and/or hypoxiaischemia between preterm and term neonates: An experimental study. J Neuroinflammation. 2011;8:55.

106. Dummula K, Vinukonda G, Chu P, et al. Bone morphogenetic protein inhibition promotes neurological recovery after intraventricular hemorrhage. J Neurosci. 2011;31(34):12068-12082.

107. Haynes RL, Folkerth RD, Keefe RJ, et al. Nitrosative and oxidative injury to premyelinating oligodendrocytes in periventricular leukomalacia. J Neuropathol Exp Neurol. 2003;62(5):441-450.

108. Ramlackhansingh AF, Brooks DJ, Greenwood RJ, et al. Inflammation after trauma: microglial activation and traumatic brain injury. Ann Neurol. 2011;70(3):374-383.

109. Gentleman SM, Leclercq PD, Moyes L, et al. Long-term intracerebral inflammatory response after traumatic brain injury. Forensic Sci Int. 2004;146(2-3):97-104.

110. Akiyama H, Barger S, Barnum S, et al. Inflammation and Alzheimer's disease. Neurobiol Aging. 2000;21(3):383-421.

111. Cagnin A, Rossor M, Sampson EL, et al. In vivo detection of microglial activation in frontotemporal dementia. Ann Neurol. 2004;56(6): 894-897.

112. Debruyne JC, Versijpt J, Van Laere KJ, et al. PET visualization of microglia in multiple sclerosis patients using [11C]PK11195. Eur J Neurol. 2003;10(3):257-264.

113. Wersinger C, Sidhu A. Inflammation and Parkinson's disease. Curr Drug Targets Inflamm Allergy. 2002;1(3):221-242.

114. Nagamoto-Combs K, McNeal DW, Morecraft RJ, Combs CK. Prolonged microgliosis in the rhesus monkey central nervous system after traumatic brain injury. $J$ Neurotrauma. 2007;24(11): $1719-1742$.

115. Nagamoto-Combs K, Morecraft RJ, Darling WG, et al. Long-term gliosis and molecular changes in the cervical spinal cord of the rhesus monkey after traumatic brain injury. $J$ Neurotrauma. 2010;27(3): $565-585$.

116. Smith $\mathrm{DH}$, Chen $\mathrm{XH}$, Pierce JE, et al. Progressive atrophy and neuron death for one year following brain trauma in the rat. J Neurotrauma. 1997;14(10):715-727.

117. Muramatsu K, Fukuda A, Togari H, et al. Vulnerability to cerebral hypoxic-ischemic insult in neonatal but not in adult rats is in parallel with disruption of the blood-brain barrier. Stroke. 1997;28(11):22812288; discussion 2288-2289.

118. Leppert D, Leib SL, Grygar C, Miller KM, Schaad UB, Hollander GA. Matrix metalloproteinase (MMP)-8 and MMP-9 in cerebrospinal fluid during bacterial meningitis: association with blood-brain barrier damage and neurological sequelae. Clin Infect Dis. 2000;31(1): 80-84.

119. Kappos L, Moeri D, Radue EW, et al. Predictive value of gadoliniumenhanced magnetic resonance imaging for relapse rate and changes in disability or impairment in multiple sclerosis: a meta-analysis. Gadolinium MRI Meta-analysis Group. Lancet. 1999;353(9157): 964-969. 
120. Blanchette M, Pellerin M, Tremblay L, Lepage M, Fortin D. Real-time monitoring of gadolinium diethylenetriamine penta-acetic acid during osmotic blood-brain barrier disruption using magnetic resonance imaging in normal wistar rats. Neurosurgery. 2009;65(2):344-350; discussion 350-351.

121. Woo MS, Wang X, Faustino JV, et al. Genetic deletion of CD36 enhances injury after acute neonatal stroke. Ann Neurol. 2012;72(6): 961-970.

122. Loane DJ, Byrnes KR. Role of microglia in neurotrauma. Neurotherapeutics. 2010;7(4):366-377.

123. Perumal OP, Inapagolla R, Kannan S, et al. The effect of surface functionality on cellular trafficking of dendrimers. Biomaterials. 2008;29(24-25):3469-3476.

124. Jain K, Kesharwani P, Gupta U, Jain NK. Dendrimer toxicity: Let's meet the challenge. Int J Pharma. 2010;394(1-2):122-142.

125. Greish K, Thiagarajan G, Ghandehari H. In vivo methods of nanotoxicology. Methods Mol Biol. 2012;926:235-253.

126. Fujitani T, Ohyama K, Hirose A, et al. Teratogenicity of multi-wall carbon nanotube (MWCNT) in ICR mice. J Toxicol Sci. 2012;37(1): 81-89.

127. Heiden TC, Dengler E, Kao WJ, et al. Developmental toxicity of low generation PAMAM dendrimers in zebrafish. Toxicol Appl Pharmacol. 2007;225(1):70-79.

128. Grether JK, Nelson KB. Maternal infection and cerebral palsy in infants of normal birth weight. JAMA.1997;278(3):207-211.

129. Paneth N, Stark RI. Cerebral palsy and mental retardation in relation to indicators of perinatal asphyxia. An epidemiologic overview. Am J Obstet Gynecol. 1983;147(8):960-966.

130. Murphy BP, Inder TE, Rooks V, et al. Posthaemorrhagic ventricular dilatation in the premature infant: natural history and predictors of outcome. Arch Dis Child Fetal Neonatal Ed. 2002;87(1):F37-F41.
131. Amarilyo G, Oren A, Mimouni FB, et al. Increased cord serum inflammatory markers in small-for-gestational-age neonates. J Perinatol. 2011;31(1):30-32.

132. Kuban K, Sanocka U, Leviton A, et al. White matter disorders of prematurity: association with intraventricular hemorrhage and ventriculomegaly. The Developmental Epidemiology Network. J Pediatr. 1999;134(5):539-546.

133. Leviton A, Kuban KC, Allred EN, et al. Early postnatal blood concentrations of inflammation-related proteins and microcephaly two years later in infants born before the 28th post-menstrual week. Early Hum Dev. 2011;87(5):325-330.

134. Menjoge AR, Rinderknecht AL, Navath RS, et al. Transfer of PAMAM dendrimers across human placenta: prospects of its use as drug carrier during pregnancy. J Control Release. 2011;150(3):326-338.

135. Chung TH, Wu SH, Yao M, et al. The effect of surface charge on the uptake and biological function of mesoporous silica nanoparticles in 3T3-L1 cells and human mesenchymal stem cells. Biomaterials. 2007;28(19):2959-2966.

136. Huang DM, Chung TH, Hung Y, et al. Internalization of mesoporous silica nanoparticles induces transient but not sufficient osteogenic signals in human mesenchymal stem cells. Toxicol Appl Pharmacol. 2008;231(2):208-215.

137. Huang DM, Hung Y, Ko BS, et al. Highly efficient cellular labeling of mesoporous nanoparticles in human mesenchymal stem cells: implication for stem cell tracking. FASEB J. Dec 2005;19(14):2014-2016.

138. Allen TM, Cullis PR. Drug delivery systems: entering the mainstream. Science. 2004;303(5665):1818-1822.
International Journal of Nanomedicine

\section{Publish your work in this journal}

The International Journal of Nanomedicine is an international, peerreviewed journal focusing on the application of nanotechnology in diagnostics, therapeutics, and drug delivery systems throughout the biomedical field. This journal is indexed on PubMed Central, MedLine, CAS, SciSearch $®$, Current Contents $₫ /$ Clinical Medicine,

\section{Dovepress}

Journal Citation Reports/Science Edition, EMBase, Scopus and the Elsevier Bibliographic databases. The manuscript management system is completely online and includes a very quick and fair peer-review system, which is all easy to use. Visit http://www.dovepress.com/ testimonials.php to read real quotes from published authors. 